\title{
Promoting the Role of the People in the Cause of Industrialization, Modernization, and Digitization for Economic Growth in Vietnam Today
}

\author{
Ha Trong Tha
}

\author{
People's Security University, Ho Chi Minh city, Vietnam \\ *Corresponding author. Email: thahuyen7775@yahoo.com
}

\begin{abstract}
Industrialization and modernization is a long-term goal of building Vietnam into an industrialized country with modern material and technical foundations, reasonable economic structure, advanced and appropriate production relations. with the level of development of production force, high material and spiritual life, strong national defence and security, rich people, strong country, democracy, justice and civilization. Vietnam is striving to the mid-21st century to become a modern socialist industrialized country, with a higher proportion of industry than other industries. In the framework of the article, the author assesses the achievements and limitations of the process of industrialization and modernization taking place in Vietnam and proposes a number of solutions to promote the role of people of all strata in this career in the current context.
\end{abstract}

Keywords: industrialization, economical modernization, digitization, role of the people, Vietnam

\section{INTRODUCTION}

Industrialization and modernization are a fundamental and comprehensive transformation process of production, business, services and socio-economic management, from the use of manual labour as a main force to the use of a how to popularize labour force with modern technologies, means and methods, based on the development of industry and scientific and technological advances, creating high social labour productivity. Industrialization and modernization are associated with Vietnam's comprehensive renovation process with the goal that by the middle of the 21 st century, Vietnam will become a modern, industrialist-oriented country [1]. With the achievements gained in recent years, is the impetus for Vietnam to be able to accomplish the set goals. However, in the context of increasing globalization and the scientific and technological revolution, some countries are moving into the knowledge economy, the later countries, like Vietnam, if they continue to develop sequentially, will lag further behind than in previous countries. Therefore, it is necessary to promote the role of the People in planning and implementing industrialization and modernization mechanisms and policies based on the knowledge economy. In particular, building and promoting the role of the working class, the peasantry, the intellectuals and the businessmen are urgent and long-term issues that need to be done regularly and consistently.

\section{ASSESS THE RESULTS OF INDUSTRIALIZATION AND MODERNIZATION PROCESS IN THE PAST TIME AND THE ORIENTATION GOALS IN THE CURRENT PERIOD}

Over the past 30 years (1986-2019), Vietnam's economic growth rate, despite certain fluctuations, still remained higher than regional and global averages with an average increase over the past period. 7\%/year. In the period 19861990, Vietnam's economic growth rate was only $4.4 \%$ /year, then in the period 1991-1995 it was 8.2\%/year; in the 1996-2000 period, it will be $7.6 \%$ /year; in the 20012005 period, it was $7.34 \%$; in the $2006-2010$ period, it will be $6.32 \%$ /year; in 2018 it was $7.08 \%$ and in 2019 it was 7.02\%. [2]

Quality of growth is gradually improved, technology level in production is raised. The contribution of total factor productivity (TFP) to GDP growth in the period 20012005 reached $21.4 \%$, in the period 2006-2010 reached $17.2 \%$, in the period 2011-2015 increased to 28 ,ninety four\%. Macroeconomic stability, inflation under control, public debt tends to decrease, foreign currency reserves increase, reaching a safe level. Average income per capita from about 100 USD / person/year in 1986, to 471 USD/person/year in 2003. In 2015, the size of Vietnam's economy reached 204 billion USD, per capita 2300 USD/person/year. In 2017, the size of the economy at current prices reached VND 5,007.9 trillion, equivalent to over $\$ 220$ billion; the average income per capita is about 2385 USD/person/year. [3]

However, the development of Vietnam's industry in recent years has not met the requirements of industrialization and 
modernization of the country, mainly developing with short-term goals and lacking sustainability; the internal strength of the industry remains weak, heavily dependent on foreign-invested enterprises; the technological level is backward and slow to be renewed; product quality, labour productivity in industry are low; industrial development has not been closely linked with other economic sectors; too focused on cheap labor, not taking advantage of the advantage in the period of golden population structure ... The efficiency of most state-owned industrial enterprises is low, many large-scale industrial projects big losses; Most domestic private industrial enterprises are small and medium enterprises; Restructuring industries is still slow; competitiveness, the ability to participate in regional and global value chains is still very limited, the main industrial production is processing, assembly and low added value; No key industry has played a leading role yet; Many industries prioritizing development do not meet the set targets; underdeveloped supporting industry, the localization rate of industries is low; Environmental pollution from industrial development is still serious.

Table 1 Growth rate and inflation rate in Vietnam during $2011-2019$

\begin{tabular}{|c|l|l|l|l|l|l|l|l|l|}
\hline Year & $\mathbf{2 0 1 1}$ & $\mathbf{2 0 1 2}$ & $\mathbf{2 0 1 3}$ & $\mathbf{2 0 1 4}$ & $\mathbf{2 0 1 5}$ & $\mathbf{2 0 1 6}$ & $\mathbf{2 0 1 7}$ & $\mathbf{2 0 1 8}$ & $\mathbf{2 0 1 9}$ \\
\hline $\begin{array}{c}\text { Growth GDP } \\
(\%)\end{array}$ & 6,24 & 5,25 & 5,42 & 5,98 & 6,68 & 6,21 & 6,81 & 7,08 & 7,02 \\
\hline $\begin{array}{c}\text { The rate of } \\
\text { inflation (\%) }\end{array}$ & 18,6 & 6,8 & 6,04 & 6 & 0,6 & 4,7 & 3,5 & 3,54 & 2,79 \\
\hline
\end{tabular}

Objectives of industrialization and modernization in Vietnam in the current period: By 2030, Vietnam will fulfil its goal of industrialization and modernization, basically becoming an industrialized country in the direction of modernization; among the top 3 countries in ASEAN in terms of industry, some of which are internationally competitive and deeply involved in global value chains. With a vision to 2045 , Vietnam will become a modern industrialized country. With the following directions: spatial distribution and industrial restructuring; select a number of priority industries for development; creating a favourable investment and business environment for industrial development; developing industrial enterprises and industrial human resources; give priority to promoting science and technology for industrial development; exploitation of natural resources, minerals and environmental protection policies; climate change adaptation in the process of industrial development; improve the Party's leadership capacity, the effectiveness and efficiency of the State's management, promote the people's mastery in formulating and implementing the national industrial development policy ... [4-5] .

\section{PROMOTE THE SYNERGY FROM THE LABOR RESOURCES IN THE CURRENT PERIOD}

\subsection{Promote the pioneering role of the working class in the cause of industrialization and modernization of the country}

By the end of 2018, Vietnam had about 13 million workers, accounting for $13 \%$ of the population and $24 \%$ of the social labour force, but the annual contribution of the working class accounted for more than $60 \%$ of the gross social product and more than $70 \%$. State budget [6]. Facing the requirements of industrialization and modernization, the working class of Vietnam has many limitations and shortcomings. "The development of the working class has not met the requirements of the quantity, structure and level of education, professional skills and occupational skills of the cause of industrialization, modernization and international economic integration. International; serious shortage of technical experts, good managers and skilled workers; industrial behaviour and labour discipline are still limited; most workers are from farmers, have not yet received basic and systematic training"[7].

Low educational level and skills of workers have negatively affected the uptake of science and technology, labour productivity, and product quality. According to the evaluation of the World Bank (WB) in 2014 on labour quality calculated on a 10-point scale, the quality of Vietnamese labour only reached 3.79 points, ranking 11/12 Asian countries in the ranking. WB rank. While South Korea reached 6.91 points, India was 5.76 points, Malaysia was 5.59 points, Thailand 4.94 points ... But according to the survey results of the International Labour Organization (ILO) In September 2014, labour productivity of Vietnamese workers was among the lowest in the region, only one fifth of Malaysian workers, 2/5 Thailand, 1/15 Singapore, 1/11 Japan, October 1 in Korea. Among ASEAN countries, labour productivity of Vietnamese workers is only higher than Cambodia and Laos. [8]

According to the Ministry of Planning and Investment, at the current rate of labour productivity growth, it is not until 2038 that the productivity of Vietnamese workers catches up with the Philippines in 2069, we will catch up with Thailand. Therefore, we need to take measures to improve the quality of human resources, contribute to improving labour productivity in the competitive process of integration. There will be a serious shortage of labour 
when large projects invested in Vietnam go into production. Currently, "The quality and effectiveness of education and training are still low compared to requirements, especially higher education and vocational education. The education and training system lacks linkage between levels and between modes of education and training; still heavy theory, lightweight practice. Training is not integrated with scientific research, business production and labour market needs" [9].

From the above situation, to develop the working class in both quantity and quality; to improve the political will, education, professional skills, occupational skills, industrial manner and labour discipline of workers, the following basic measures must be implemented:

Firstly, promoting industrialization, modernization and international integration associated with the development of the knowledge economy. First of all, priority should be given to the development of labour-intensive industries to create jobs, promoting the national competitive advantage of labour resources, contributing to rapid labour restructuring, continuing developing a number of labourintensive industries. This is considered a condition for using labour resources at all levels, rational distribution of labour among regions, sectors and economic sectors.

Secondly, focus on developing the contingent of workers in the state economic sector. The process of innovation and integration has affected the change of the working class of Vietnam in the direction that the number of workers in the state-owned economy is decreasing in number, while the workers in the private economic zone and Foreign-invested economy has developed very fast in both quantity and quality. This more or less affects the core role of the contingent of workers in the state economic sector to the leading role of the state economy. In the coming time, the process of restructuring and rearranging state-owned enterprises will have more impact on the contingent of workers in the state-owned economy, but the general situation will gradually stabilize. If SOEs are restructured and restructured, they will bring about efficiency in production and business. With its position in the structure of a multi-sector economy, state-owned enterprises need to be at the forefront of applying scientific, technological and managerial achievements and at the same time expanding their production scale export. That process will contribute to stability, step by step developing the contingent of workers in the state-owned economy in both quantity and quality. At that time, the state economy will promote its leading role, regulate the economy and the contingent of workers in state-owned enterprises deserves to be a core force, leading the process of promoting industrial career, modernize the country.

Thirdly, innovating and improving the quality of education and training, especially human resource training. One of the main causes of human resources in general, the country's working class in particular in recent years has not met the requirements of the country's construction and development process is education and training many limitations and inadequacies. Therefore, Vietnam needs to renovate the content, programs and methods of training human resources in general, for the working class in particular. There is a need for an overall evaluation from general education to vocational education. It is important to shift the education process primarily from equipping knowledge to fully developing competency and quality of learners; learn with practice, reasoning associated with practice. Putting the contents of the science and technology revolution into the curriculum so that after graduation, this human resource can be used immediately in the production labour process. Collaborate between enterprises as employers and the state and training facilities to train human resources according to social needs. Direction of training associated with employment, training with use, and training according to social needs. Formulating a vocational training project based on social needs, in which education and training development must be associated with socio-economic development needs.

Making predictions about human resource needs, from which appropriate guidelines and policies in training to meet social needs, to avoid wasting training as before. Strengthening training and retraining of a contingent of workers in terms of quantity, quality assurance, uniformity in structure and highly qualified workers. Open schools to train young workers, create a rich and quality supplementary source. Encouraging and creating conditions for workers to self-study to improve their skills and retrain workers who have not met the requirements of the revolutionary career. This is a difficult task, requiring large-scale investment, from education and training strategies to implementation models and modes.

The working class of Vietnam has been and has been an important transformation, continuing to promote its role as the revolutionary leadership class. Developing the Vietnamese working class to grow in both quantity and quality so that they deserve to be the leading force in the cause of industrialization, modernization and international integration.

\subsection{Enhancing the role of farmers in the process of agricultural and rural industrialization and modernization in Vietnam}

Today, in the process of industrialization and modernization of agriculture and rural areas, farmers are still a large and core force and mainly participate directly in this process. Achievements in the process of implementing the cause of industrialization and modernization of agriculture and rural areas have made a proud contribution of farmers. In order for the process of agricultural and rural industrialization and modernization in Vietnam to go deeper, continue to achieve even greater achievements, requiring synchronous solutions:

Firstly, to continue implementing the Resolution of the 7th plenum of the Central Party Congress $\mathrm{X}$ "on agriculture, farmers and rural areas" with the viewpoint affirming the role of farmers in agricultural and rural development and highlighting the State's responsibility to farmers. In the close relationship between agriculture, 
farmers and rural areas, farmers are the subjects of the process of developing and building new rural areas. Addressing agriculture, farmers and rural areas is the task of both the political system and the whole society; First of all, to arouse the spirit of patriotism, self-reliance, selfreliance and self-reliance of farmers.

Promote the strong development of the agricultural economy, in association with the construction of new rural areas in the spirit of the Resolution of the 12th National Assembly of the Party: "Accelerating the restructuring of the agricultural sector, building a comprehensive ecological agriculture, increase productivity, quality, efficiency and competitiveness... improve the income of farmers. Transforming rural economic structure associated with building new rural areas ... Promoting the subjective role of farmer households and household economy" [10]. Secondly, continue to develop and perfect policies to ensure the rights and legitimate interests of farmers. Policies on land use rights; policies combining small household economy with enterprises in production, harvesting, storage, processing and consumption of products; effective coordination between 4 houses (agriculturalists, entrepreneurs, State and scientists); social security policies for farmers such as health insurance, support to poor children in education, support for vocational training and job seeking, insurance for farmers when the State recovers land for use for other purposes.

Take care of material and spiritual life for rural people, invest in developing socio-economic infrastructure; renovate and improve the quality of education and vocational training. Implement training links with universities, vocational training centers, community learning centers to enrich the culture and raise the intellectual level for farmers.

Thirdly, strengthening solutions to support farmers to boost production in the process of industrialization and modernization. Mechanisms need to be built, creating close relationships between "houses", especially between farmers and businesses and traders. Increasing support for farmers through agricultural extension programs; promote training, popularize the application of scientific and technical advances, build model farming models for farmers to study.

The State needs to increase investment capital, create favourable conditions for farmers to access and fully update market information; improve Vietnam's agricultural competitiveness on domestic and foreign markets, protect domestic markets and develop agricultural export markets. Promulgating appropriate policies on agricultural land; ensure reasonable prices for major agricultural products and materials for agriculture.

Supporting farmers to get credit loans for production and business capital. The forms of lending must be diversified and the loan procedures are simple; at the same time, it is necessary to reduce the contributions of farmers to create conditions for them to invest in production and business.

Fourthly, promoting democratization in order to enhance the initiative and creativity of the peasantry in the period of industrialization and modernization. Local governments should create favourable conditions for Farmer's Unions to participate in the formulation, supervision and social criticism of policies and programs on rural construction, agricultural insurance and voluntary social insurance to advance to pensions-free farmers. The Association needs to do better the propaganda, advocacy and gathering of peasant classes to promote the patriotic tradition, hardworking, creative labour force, well implement the Party's guidelines and policies, laws of the State; at the same time take care and protect the rights and legitimate interests of farmers.

It is necessary to create a democratic and equal environment so that every citizen has the opportunity to promote their capacity, offer initiatives and experiences in the production labour process, well perform the role of the subject in building new rural areas. . Continue to strictly implement the Ordinance on the implementation of democracy in communes, wards and towns. Arouse and effectively use all potentials of farmers. Encourage and encourage active forces to participate in building a cultural environment, promoting patriotic traditions, diligence, creativity, solidarity, solidarity in labour and production; democratize the spiritual life in the countryside, build a strong agricultural cooperative.

\subsection{Building an increasingly strong and high- quality intellectual team to meet the requirements of industrialization and modernization}

The intellectual team is an important resource, reflecting the strength of each nation, especially in the current global competition. In the process of industrialization and modernization, the intellectual team is the nucleus of innovation, leading the research, application, reception and transfer of scientific and technological advances in many fields. Various, creating a driving force for rapid and sustainable development. In order to promote the position and role of the intellectual team in the coming time, it is necessary to continue to perform better a number of following tasks:

Firstly, to continue to thoroughly grasp and enhance the propagation, inspection, supervision and organization of seriously and synchronously implementing effectively the Party's resolutions on the development of intellectuals. Raising awareness and creating a high unity in the political system and people of all classes on the consistent policy of developing the intellectual contingent of the Party and the State: "Building a strong contingent of intellectuals is direct. Improve the intellectual level of the nation, the strength of the country, enhance the leadership of the Party and the quality of operation of the political system; investing in building intellectuals is an investment in sustainable development" [4].

Secondly, improving the responsibilities and contributions of the intellectual team, consolidating the organizational system of intellectual associations to meet the requirements of the country's sustainable development in the new period. Enhancing ideological activities for 
intellectuals, especially leading intellectuals and young intellectuals; raise the political awareness and responsibility of this team. Improve the effectiveness of consultancy, criticism, social assessment activities and information dissemination activities of intellectual associations.

Third, continue to improve institutions, mechanisms, policies and laws that respect intellectuals and talented people; create favourable legal corridors for organizing professional scientific forums. Building democratic regulations in science - technology activities, education training, culture - arts activities; respect and promote the autonomy in research, creation, consultancy and criticism activities of intellectuals and scientists. To formulate a specific mechanism on investment and remuneration for intellectuals according to creative tasks and products, suitable to each subject.

Fourthly, promote mobilization and diversification of investment resources for building and developing intellectuals. The State gives priority to balancing development investment capital in infrastructure and working environment in service of intellectual research and creation activities; to soon invest in building scientific-production complexes and modern cultural centers for the socio-economic regions of the country in order to promote research, absorption, transfer and dissemination of knowledge to serve develop the country. Fifthly, soon develop a National Strategy for the development of intellectuals for the period of 2021-2030 in line with the country's Socio-Economic Development Strategy in the new period; focus on the industries and fields that are lacking, imbalanced, and irrational in structure; to prioritize the development of a contingent of ethnic minority people and female intellectuals; prioritize industries and sectors that meet the requirements of the fourth industrial revolution.

In the face of rapid changes in the international and domestic situation, the cause of industrialization and modernization of the country has always posed many new issues that need to be completed, supplemented and developed. This is closely related and indispensable to the participation and contribution of intellectuals and scientists. Vietnam always respects and expects from the team of people with "high minds and minds" - truly "the national spirit" in the cause of industrialization, modernization, rapid and sustainable development of the country.

\subsection{Building and promoting the role of the Vietnamese business team in the period of accelerating industrialization, modernization and international integration}

Entrepreneurs force an important role in the cause of industrialization and modernization of the country. Building a strong team of entrepreneurs, who are competent, qualified, qualified and highly reputable will actively contribute to improving quality, efficiency, competitiveness, rapid development, sustainability and independence. , autonomy of the economy. In other words, promoting the country's economy to develop and creating Vietnam's position on the world economic map is the mission and responsibility of the businessmen and business community.

Over the past years, Vietnam has had many guidelines and policies to encourage enterprise development, promoting the role of the business team, so that Vietnamese businesses have really had a strong development step. . It is not only more than 700,000 businesses but also includes more than five million business households, including 1.6 million registered business households. Businesses of various types are contributing more than $60 \%$ of GDP, about $70 \%$ of state budget revenues, creating tens of millions of jobs and playing a key role in national economic growth, contributing greatly contributing to the process of industrialization, modernization of the country, hunger eradication and poverty reduction, ensuring social security [5]. In the context of strong international integration today, when Vietnam participates in large "playing fields" such as the Comprehensive and Progressive Agreement for Trans-Pacific Partnership (CPTPP) or the European Union Vietnam Free Trade Agreement (EVFTA) ..., the role of the business team is increasingly clear, expressing the desire to rise up to compete fairly with rivals, improve Vietnam's position in the international arena.

Vietnam's extensive international economic integration has brought many opportunities, but also posed many difficulties and challenges for the Vietnamese economy in general and Vietnamese enterprises in particular. Recognizing that the entrepreneurial team is the representative of new production in a socialist-oriented market economy, is one of the decisive factors to implement the industrialization strategic goals, modernizing and integrating into the world, building a strong entrepreneur force is a breakthrough that contributes to the country's development, fights the risk of falling behind, and enhances Vietnam's position in the new era. Developing a team of entrepreneurs that can take on that responsibility is a particularly important task.

Firstly, continue researching and perfecting the market economy institution, at the same time with the transparent disclosure of orientations, socio-economic development planning, supportive policies, creating conditions for the enterprises of all economic sectors have equal access to development resources. Studying and perfecting the law on ownership, business rights, creating a legal 
environment for fair and fair competition, eliminating business privileges and monopolies. Continuing administrative reform, ensuring agencies and public service executives supporting and accompanying entrepreneurs. Building and implementing a good mechanism of dialogue, consultation of entrepreneurs in the process of promulgating and organizing the implementation of policies and laws.

Secondly, build a system of measures to support entrepreneurs to participate in the official business area, expand the scale, improve the performance of businesses, and focus on developing entrepreneurs in rural areas. Encourage business cooperation, merger and acquisition and take appropriate measures to quickly increase the number of medium-sized businesses; promote the formation and development of a number of large enterprises capable of leading and supporting small and medium-sized enterprises to deeply participate in the global supply chain.

Thirdly, create a fundamental change in training and fostering entrepreneurs. Develop and implement a national program on entrepreneur training, gradually approaching international standards. Innovating the content of training programs and methods on economics and business administration at universities, colleges, vocational secondary schools and vocational schools. Focusing on ethical education, sense of responsibility, honesty, cooperative spirit, national awareness, sense of community of businessmen. Promoting business culture and social responsibility of entrepreneurs, building harmonious labour relations, environmental protection and sustainable development. Develop regulations and guidelines, manage activities honouring businesses and entrepreneurs, ensuring practical efficiency.

Fourthly, promoting the role of the system of organizations representing the business community and the contingent of business people, guiding and supporting the establishment and association of business associations; expand political campaigning among business people; collect and reflect aspirations, ideas and recommendations of business people, advise the Party and the State on socio-economic policies; implement measures to promote enterprise and entrepreneur development.

Fifthly, strengthening the Party's leadership for the career development of the business team. Develop and implement a strategy to develop the business team; institutionalizing the policy lines for the Party's businessmen with specific action plans; Strengthening the representation of businessmen in the structure of organs of the political system.

Sixthly, each business owner should be aware of improving his / her education, specialized knowledge, cultural, economic, legal and social knowledge ... According to the results of the General Department's Economic Survey Statistics: Small, medium and micro enterprises accounted for the largest proportion of $98.1 \%$ (507.86 thousand enterprises); in which medium enterprises have nearly 8.5 thousand enterprises, accounting for $1.6 \%$; small enterprises were 114.1 thousand enterprises, accounting for $22 \%$ and micro enterprises were 385.3 thousand enterprises, accounting for the highest with $74.4 \%$ [4]. Thus, at present, Vietnam has the largest proportion of micro enterprises, most of which go up to individual business households or come from business ideas of individual owners enterprise. Entrepreneurs - business owners more than anyone else in the business need to be conscious of improving their education and professional qualifications in the field of production and business of their businesses, need to learn new knowledge., applications of science and technology to improve product quality, cost savings...

Entrepreneurs should proactively equip knowledge of accounting and finance, corporate governance, human resource management, knowledge of law-making economics, social culture, corporate culture ...; regularly update new knowledge, hone the necessary skills to be strong enough to "stand firm" and improve competitiveness in the market.

\section{CONCLUSION}

Vietnam has moved up to socialism from an outdated agricultural country, inferior facilities and technologies, the level of underdeveloped production force and newly established socialist relations not yet completed. Therefore, the process of industrialization is the process of building material and technical foundations for the national economy. Each step of the process of industrialization and modernization is a step of strengthening the material and technical foundations for socialism, developing a strong production force and contributing to perfecting the social production relations tenet.

In the trend of regionalization and globalization of the economy, which is developing strongly, under the conditions of modern scientific - technical revolution and modern technology development; objective and subjective advantages and difficulties, opportunities and risks, both creating new opportunities and obstructing and challenging our economy, intertwined move each other. Therefore, Vietnam must take initiative in creativity to seize opportunities, promote advantages to accelerate the process of industrialization, create a new position and force to overcome difficulties, reverse risks, bring the economy economic growth, sustainable development.

\section{REFERENCES}

[1] Vietnamese Communist Party, Document of the 11th National Congress, National Political Publishing House, Hanoi, 2011, p. 71.

[2] Vietnam Statistical Yearbook through the years and the Socio-Economic Development Report of the years on the website of the Government and the Ministry of Planning and Investment. 
[3] Socio-economic development reports for years on the Government's website and the Ministry of Planning and Investment.

[4] General Statistics Office: Statistical Yearbook 2018, Statistical Publishing House, Hanoi, 2019

[5] Mazyrin, Vladimir M. Economic Modernization in Vietnam from Industrialization to Innovation Stage. VNU Journal of Science: Economics and Business, [S.1.], v. 29, n. 2, june 2013. ISSN 2588-1108.

[6] ADB (2007), "Agricultural land conversion for industrial and commercial use: Competing interests of the poor", In ADB (Ed.), Markets and Development Bulletin (pp. 85-93), Hanoi, Vietnam: Asian Developmen Bank.

[7] Socio-economic development reports for years on the Government's website and the Ministry of Planning and Investment.

[8] Kenichi Ohno. Avoiding the Middle-Income Trap: Renovating Industrial Policy Formulation in Vietnam. ASEAN Economic Bulletin. Vol. 26, No. 1, Vietnam: Coping with Domestic and External Challenges (April 2009), pp. 25-43

[9] Tran K D. Vietnamese Schooling in Transition: Industrialization and Modernization. CICE Hiroshima University, Journal of International Cooperation in Education, Vol.11 No.1 (2008) pp.85 96

[10] C. Y. Ng, Nick J. Freeman, Frank C. H. Huynh. State-owned Enterprise Reform in Vietnam: Lessons from Asia. Institute of Southeast Asian Studies, Singapore. 1996. $170 \mathrm{p}$. 